\title{
CrimRxiv
}

\section{REDUCING VIOLENCE}

WITHOUT POLICE: A

REVIEW OF RESEARCH

\section{EVIDENCE}

John Jay Research and Evaluation Center

Published on: Nov 09, 2020

DOI: $10.21428 / c b 6 a b 371.637 c 2 b 44$

License: Creative Commons Attribution 4.0 International License (CC-BY 4.0). 
